\title{
The Challenge of Global Selective Outsourcing Environment: Implementing Customer-Centric IT Service Operations and ITIL Processes
}

\author{
Anne-Maarit Majanoja ${ }^{1 *}$, Erkki Tervala², Linnéa Linko ${ }^{3}$, Ville Leppänen ${ }^{1}$ \\ ${ }^{1}$ Department of Information Technology, University of Turku, Turku, Finland \\ ${ }^{2}$ IT Quality and Outsourcing Management, Oulu, Finland \\ ${ }^{3}$ Turku Centre for Biotechnology, University of Turku, Turku, Finland \\ Email: anne-maarit.majanoja@outlook.com
}

Received 14 October 2014; revised 12 November 2014; accepted 2 December 2014

Copyright (C) 2014 by authors and Scientific Research Publishing Inc.

This work is licensed under the Creative Commons Attribution International License (CC BY). http://creativecommons.org/licenses/by/4.0/

(c) (i) 0 pen Access

\begin{abstract}
Presently, internal Information Technology (IT) organizations make strategic level decisions to explore new capabilities and solutions from outsourcing markets to fulfill various business and customer expectations. However, far too little is known about the operational level challenges that emerge between IT service purchasing companies and suppliers in a global selective outsourcing environment. In this research, we focus on analyzing the operational level challenges and nonconformances from the IT service purchasing company's point-of-view. Nokia's IT unit selectively outsourced parts of its operational level IT service activities to the supplier. The IT unit and the supplier jointly implemented Information Technology Infrastructure Library (ITIL) processes, globally. The cooperation was not completely trouble-free. It was identified that ITIL processes can provide standardized structures for executing the IT service activities, but quality and customer-centric operation will also require active and participative management and leadership, efficient communication and information sharing, globally implemented quality management practices, and clear responsibility and ownership structures between the parties. These findings improve operational level selective outsourcing knowledge, and the findings can be exploited by other global IT service transition projects.
\end{abstract}

\section{Keywords}

IT Service, ITIL Processes, Selective Outsourcing, Quality Management, Customer Satisfaction

\footnotetext{
${ }^{*}$ Corresponding author.
} 


\section{Introduction}

Recent years have witnessed how companies have shifted their focus on core competencies, and internal Information Technology (IT) departments are looking for solutions from global outsourcing markets. Several internal application development and service activities have been increasingly outsourced to external service providers (later referred as supplier) and their offshore competence centers. Selective outsourcing, where some of the service purchasing company's activities and assets are outsourced to be performed by suppliers but the ultimate responsibility and ownership of the IT applications, services, and outsourced activities and assets remains with the service purchasing company, can dramatically increase the amount of participants and stakeholders in a company's IT demand-supply structure. This demand-supply structure includes, for example, service purchasing company's personnel, suppliers' personnel, operational level activities, and information to produce the needed products and/or services. Therefore, successful selective IT outsourcing operation requires continuous relationship management between the parties.

Companies are seeking ways to assure standardized service delivery to their customers. Presently, Information Technology Infrastructure Library's (ITIL) best-practices and processes are used to standardize IT service deliveries and to achieve business targets. Worthen [1] wrote that ITIL helps IT departments to improve, for example, service quality, project deliverables and resource utilization. It also helps to decrease the need of rework and to provide services that meet the service purchasing company's expectations. Nevertheless, these various tools, techniques, and best practices alone will not solve all challenges that companies may encounter during their operations. Successful operation is based on the same set of required targets, practices, and quality standards that all stakeholders will follow. Companies also need to focus on several other activities, such as, customer-centric operation, ensuring senior executives' commitment, active and participative leadership, and communication to implement the required practices and standards into the outsourcing mode-of-operation.

The complexity of this demand-supply structure impacts significantly and directly on IT service purchasing company's perception, trust, quality, results, performance, and finance. Because of this, focusing only on IT service purchasing company's internal quality activities and operation management is not sufficient. The quality management activities may include, for example, various coordinated activities and requirements, quality policies, and quality objectives that should be extended to include the entire IT demand-supply network, globally. So far, however, far too little attention has been given to the operational level challenges between service purchasing companies and suppliers in a global selective outsourcing environment, and how the companies define and implement common operational level practices.

We used an action research method, interviews, questionnaires, and the authors' knowledge and hands-on experience to present the identified challenges, constraints, and actions during the global ITIL process implementation and mode-of-operation transformation. This research analyzes the emerged challenges, global selective outsourcing cooperation approach, and how the challenges and mode-of-operation impacted on the IT service purchasing company's satisfaction results. In this research, we used instances and illustrations from Nokia Devices and its IT unit. Nokia implemented several outsourcing initiatives during years 2009-2011, and therefore, it was an ideal case company to analyze various operational level challenges. However, we focus only on analyzing the situation between the IT unit and the supplier. We will not expand upon Nokia's customers (such as intermediate (trade) customers and end-consumers). Similarly, we will not expand upon Nokia's mobile phone Research and Development (R \& D) and marketing, mobile phone manufacturing and logistics, or its overall leadership. We have also limited our focus on analyzing the operational level challenges that emerged during the implementation of the jointly defined ITIL processes and mode-of-operation practices in a selective outsourcing environment. Therefore, in this research we will not present the next steps and analyze the implemented corrective actions, which were implemented after the interviews and root-cause analysis activities.

During the year 2008, Nokia's management decided to streamline its IT organization as a target to increase operational efficiency and reduce operating costs, and to create a new outsourcing strategy based on Nokia's scope and targets. As part of the planned changes, the case IT unit (which was part of the IT organization) selectively outsourced its IT application development and IT service maintenance and support activities to a new supplier. The overall IT operations and service management responsibility was retained in-house as part of the IT unit's ownership. However, the operational level execution interface changed. The operational level activities, roles and responsibilities, and management were divided between the IT unit and the supplier. This kind of selective outsourcing operation environment in this research is called as integration-outsourcing environment. To 
establish and manage the integration-outsourcing activities at Nokia, widespread changes were required to create a new IT outsourcing strategy, a new governance and leadership approach, and globally implement the needed IT service processes and practices.

The paper has been organized in the following way. Next, the paper will lay out the theoretical dimensions of the research, and then introduces the research hypothesis. It will then go on to the research, findings, results and analysis. Finally, we conclude by validating the findings.

\section{Literature}

\subsection{IT and Outsourcing}

Currently, a great number of internal IT organizations are acquiring new capabilities from the IT outsourcing market. According to the Gartner's [2] forecast, worldwide IT spending was estimated to total of \$3.7 trillion in year 2014, and a 2.1 percent increase from 2013 spending. Similarly, Gartner [3] wrote that the worldwide IT outsourcing (ITO) market would reach $\$ 288$ billion in 2013, a 2.8 percent increase from year 2012. Davenport [4] identified that companies decide their outsourcing capabilities based on two criteria: 1) Faith that the external provider will do a good job, and 2) Cost. When comparing these two criteria, currently the cost and cost reduction objectives seem to be the main motivation behind outsourcing decisions.

Sousa and Voss [5] identified five outsourcing elements: 1) Outsourcing is implying a business relationship between the parties; 2) Outsourcing focuses on general business processes or processes' results (core activities and support processes, such as, R\&D, manufacturing, IT, and logistics); 3) Outsourcing is not a simple purchasing decision; 4) The outsourced objects are specific to the outsourcer/customer; and 5) The outsourcer/customer may outsource all or part of a process or process result. Outsourcing creates inter-organizational relationships between the parties, and therefore communication and trust between the parties needs to be successful. McIvor [6] identified that in a business process outsourcing (BPO) situation a supplier takes the responsibility to execute the business processes (for example, customer services), and there are three BPO models: 1) Selective outsourcing (a limited number of outsourced activities); 2) Transitional outsourcing (temporarily outsourcing the process to a supplier); and 3) Total outsourcing (outsourcing the entire process to a supplier). Based on this, both Sousa and Voss and McIvor identified selective outsourcing as a typical outsourcing form.

Several risks and challenges are also associated with IT outsourcing. Han and Mithas [7] pointed out that despite of the outsourcing contract or the suppliers' resources, a service purchasing company still needs some internal employees to drive the company's interest and to ensure that the suppliers continue to make business relationship investments. Similarly, Gopal and Gosain [8], Oshri et al. [9], and Hand and Mithas [7] have identified that internal IT personnel are needed to provide trustworthy boundary-spanners between the service purchasing company's business functions and the supplier, and bridging the knowledge gap (such as, technical and business knowledge) between the supplier and the customer. McIvor [10], Ang and Cummings [11], and Jap and Anderson [12] wrote that a supplier may seek possibilities to standardize the transferred assets to achieve greater financial benefits by providing lower performance levels and low quality goods or services. This kind of behavior can increase the potential for opportunism, and companies have to create complex contracts to protect themselves from the supplier's potential opportunism.

Veltri et al. [13] have studied companies that decided to backsource their outsourced activities. Their empirical studies identified various outsourcing related problems and reasons for dissatisfaction, such as: The outsourcing contracts did not live-up-to expectations because the provider was unwilling or unable to perform as expected, the costs were higher than originally expected, the service quality was poor, the loss of control, or the providers were incompetent. Davenport [4] stated that a lack of required activity standards and descriptions may cause dissatisfied outsourcing relationships. Therefore, clear descriptions and standards are needed for ensuring effective communication and cooperation between the parties.

\subsection{ITIL Based Mode-of-Operation}

ITIL processes are widely used in IT service management to standardize IT services. ITIL is a set of best practices and processes for IT service management (ITSM) to align IT services with the business needs. Various organizations, globally, are using ITIL based practices to respond to customer service needs and business targets [14]. An Introductory Overview of ITIL V3 [15] documentation defines: "A service is a means of delivering 
value to customers by facilitating outcomes customers want to achieve without the ownership of specific costs and risks. Service Management is a set of specialized organizational capabilities for providing value to customers in the form of services.” Although ITIL brings several best practices, implementing only the ITIL processes and practices is not a path to successful end-result.

Sharifi et al. [16] collected a list of practical ITIL implementation issues, for example, lack of management commitment, spending too much time on defining complicated process diagrams, not creating work instructions, not assigning process owners, concentrating too much on performance, being too ambitious, and ignoring solutions other than ITIL. Therefore, ITIL based mode-of-operation implementation is a massive transformation project. Sharifi et al. [16] wrote that the majority of IT monitoring activities concentrates on performance, and ignores quality and processes. ITIL recognizes several frameworks, for example, Control Objectives for Information and Related Technology (Cobit), Six Sigma, International Organization for Standardization (ISO) 9000, and ISO 20000, which can be used to develop quality management practices. Clearly, the operational level main point should be the quality of outputs, not the name of a framework or a standard. Therefore, other applicable practices and frameworks, in addition to ITIL, should also be exploited and focus more attention on quality management practices.

Ensuring management's commitment and continuous support are critical when implementing ITIL practices into the operation [17]. Successful implementation requires a lot of planning, communication, training, and change management activities. Companies should perceive the amount of processes they need to deliver the services, and how complex and detailed the needed process descriptions should be. As stated by Sharifi et al. [16]: "It is better to have written, published, and continually reviewed work instructions". Instead of spending majority of the time to draw detailed ITIL process diagrams, companies should spend time on creating clear work instructions and describing the needed roles and responsibilities in their global operations. The ITIL planning to implement service management guidelines [18] document, for example, does not give exact and all-inclusive ITIL process and practices implementation instructions and activities, because it is always a time, situation, context, and company specific solution.

Companies may attempt to implement all or majority of the defined ITIL processes at once. In practice, the implementation and transformation will not happen quickly. Sharifi et al. [16] estimated that it would take three to five years to implement all of the ITIL processes. Shang and Lin [19] identified that there is an imbalance between ITIL principles and customers' expectations. The main ITIL objective is to record customers' problems and corresponding solutions into a database where the solutions can be retrieved if the problem reoccurs. However, the customer expects efficient and timely communication instead of waiting that the problem and solution are first recorded into the database. The challenge is that ITIL focuses on IT related problem solving instead of customer-centric communication, but customers' perception is at the end formed based on direct communication and service [20] [21]. This indicates that customers' satisfaction is not solely dependent on the speed of problem-solving, technical solutions, or used processes and practices. Instead, direct and timely interaction, soft skills, and efficient communication are critical in successful customer-centric operation.

\section{Methodology and Research Hypothesis}

In this research, the three main research methods are: Quantitative, qualitative, and mixed methods [22] [23]. Qualitative and quantitative methods have limitations to drill down into real-world's situations. The action research method can be used to achieve deeper operational level knowledge, and participation is fundamental to action research. Näslund [24] and Meyer [25] describe that the action research method requires researcher to perceive the need of change and being active member in the change process. Typically, a researcher studies the organizational phenomena without changing it, but an action researcher is actively involved in the organizational changes while studying the process.

Interviews are one of the most common strategies for collecting qualitative data. Qualitative interviews are typically categorized as 1) unstructured, 2) semi-structured, and 3) structured interviews [26]-[28]. The target of questionnaires is to collect information that can be quantified and subjected to statistical treatment [29] and the researcher tends to capture the current phenomena. Therefore, questionnaires can offer an objective means to collect information about people's knowledge, beliefs, attitudes, and behavior.

In this research, we used semi-structured interviews and questionnaires to collect the research information. During the analysis phase we analyzed the jointly developed ITIL processes and Service Level Agreement me- 
trics and Key Performance Indicators. We also utilized the action research method and the authors' hands-on experience to observe, analyze, and present the IT unit's satisfaction results and the impacts of ITIL process implementation on the global integration-outsourcing environment. This study suggests that the hypothesis may be associated significantly with change implementation success and performance:

H1: In an integration-outsourcing environment, merely implementing ITIL processes and standardizing services will not assure the IT service purchasing company's satisfaction, and therefore ITIL implementation should be supported with clearly defined operational level responsibilities and global coordination, extensive and timely training and information sharing, and not outsourcing quality and customer-centric operations.

This research may not be classified as a full case study, because it only presents short illustrations, analyses, and evaluations of the activities and outcomes from the case units at Nokia (before the assets were sold to Microsoft). The activities and evaluations in the case units were performed by a group at Nokia Devices during years 2009-2011. Nokia and Microsoft have many competitors, and therefore the companies are restrictive to make public their successes and failures, especially when it comes to their core processes. This restricts the scope and possibilities to present the Nokia results and implemented operational level activities in full detail.

\section{Case Study}

\subsection{Defining a Global IT Service Strategy and Practices}

At Nokia, the internal IT organization was divided into several IT units. The IT unit was responsible for several global end-consumer (later referred also as customer) applications and services, such as help-desk services. The personnel of Nokia's businesses and IT units jointly participated in the IT application and service development activities. For example, the business process owners were responsible for developing the business processes, acceptance testing, and managing the business side communication and training. During the development activities, the IT unit's personnel were responsible for technical tasks, such as: application development, testing and integration management, and test and production environment deployments. Based on the business roadmaps the IT unit evaluated the business requirements, and estimated the possible technical change impacts on IT applications and services. The IT unit was responsible for business relationship management, and all IT related tasks and activities were first prioritized and instructed by the IT unit before selectively outsourcing those to the suppliers.

At Nokia, the IT organization was responsible for the IT supplier management activities. Therefore, the IT unit was responsible for agreeing outsourcing contracts with the IT suppliers, if the applications and/or services were owned by the IT organization. The suppliers provided the needed outsourcing resources (onsite and offshore), technical skills, and consultancy services. If the IT unit had a team, for example, in the USA, the supplier's onsite personnel were able to visit the Nokia premises and work locally. The offshore personnel worked at the supplier's offshore facilities without having a daily face-to-face interaction with the IT unit's or the supplier's onsite personnel.

During the year 2008, Nokia's IT management made a strategic decision to use only few preferred suppliers to deliver the needed IT services. The IT organization's target was to purchase 70 - 80 percent of the IT development and service activities from these preferred suppliers. In addition to the preferred suppliers, a list of "accepted suppliers” was also available for special service needs (such as special technology requirements). All preferred suppliers offered also offshoring services, and their main offshoring countries were India and China.

During years 2008-2009, the IT unit selected its supplier based on several service offers. All preferred suppliers gave an offer and described how they would deliver the planned IT application development and service delivery activities including the IT service delivery cost calculation proposals. The suppliers also described how they would manage the needed knowledge-transfer activities from the current supplier. The IT unit evaluated and screened the suppliers and their offers based on various entities, for example: Technical skills, flexibility, delivery models, pricing structures, internal processes, standards and certifications, and possible location specific risks. During the evaluation phase, the offshore sites were visited to achieve better first-hand knowledge of the suppliers' offshore facilities, infrastructure, and business practices. After the supplier selection, the necessary frame agreements and outsourcing contracts were created, and the selected supplier started the knowledgetransfer activities. According to the service agreements, the supplier was responsible for the operational level IT application maintenance and service support activities and management.

We emphasize that the IT services were 100 percent owned by the IT unit, and the IT unit was accountable for 
service development roadmaps, application and service ownership, end-customer and business unit satisfaction, and reporting to the Nokia's top management. We identified that the integration-outsourcing mode-of-operation model included jointly defined processes and practices, but it also included several internal processes and practices that significantly impacted on the daily cooperation. In fact, both of the companies had their own internal processes and practices, which they had to follow. These internal processes and practices were not necessarily shared to the other party. The service resourcing was divided between the IT unit and the supplier. The IT service management and steering were managed by the IT unit's personnel and, for example, the product and service managers came from the IT unit instead of the supplier's team. The supplier's service support personnel (called as Tier 1, Tier 2, and Tier 3) worked at the supplier's offshore competence centers. In addition to the supplier's support teams, the customer account manager (the IT unit's main contact point), onsite development personnel, and the global teams (such as, global quality team) strongly influenced on the overall cooperation.

Figure 1 gives a generic illustration of the integration-outsourcing environment. As can be seen, both of the companies had their own blocked internal processes and practices, and the other party was not able to see or impact on those. The integration-outsourcing environment was established based on mutually agreed novel processes and practices. Even though the IT unit owned the services, the supplier's internal processes and practices were not part of the IT unit's sphere of influence (for example, how the supplier was resourcing the support teams). Nevertheless, both of the parties were expected to actively manage the integration-outsourcing operation and operational level activities. The global service delivery teams, which included the IT unit's personnel and the supplier's onsite and offshore personnel, jointly operated according to the novel set of ITIL processes and practices and mode-of-operation approach.

To be more precise, this integration-outsourcing situation was not a total outsourcing solution where the IT unit merely received the outcomes. At the end, the IT unit was accountable for service deliveries and facing the possible impacts coming from the customers and business units if the service levels did not meet the expectations. The IT service purchasing company had the main steering power and was accountable for performance and service status levels. Therefore, it was critical for the IT unit to have the needed operational level visibility, globally.

When IT services are completely managed and executed internally (in-house), the internal team is able to ensure the needed level of end-to-end service management visibility. However, in this kind of integration-outsourcing situation, the IT service purchasing company did not hold a similar kind of end-to-end visibility and power, because the operational level activities were performed by the supplier's personnel. Therefore, in an integration-outsourcing environment, the IT service purchasing company has only a partial visibility and power

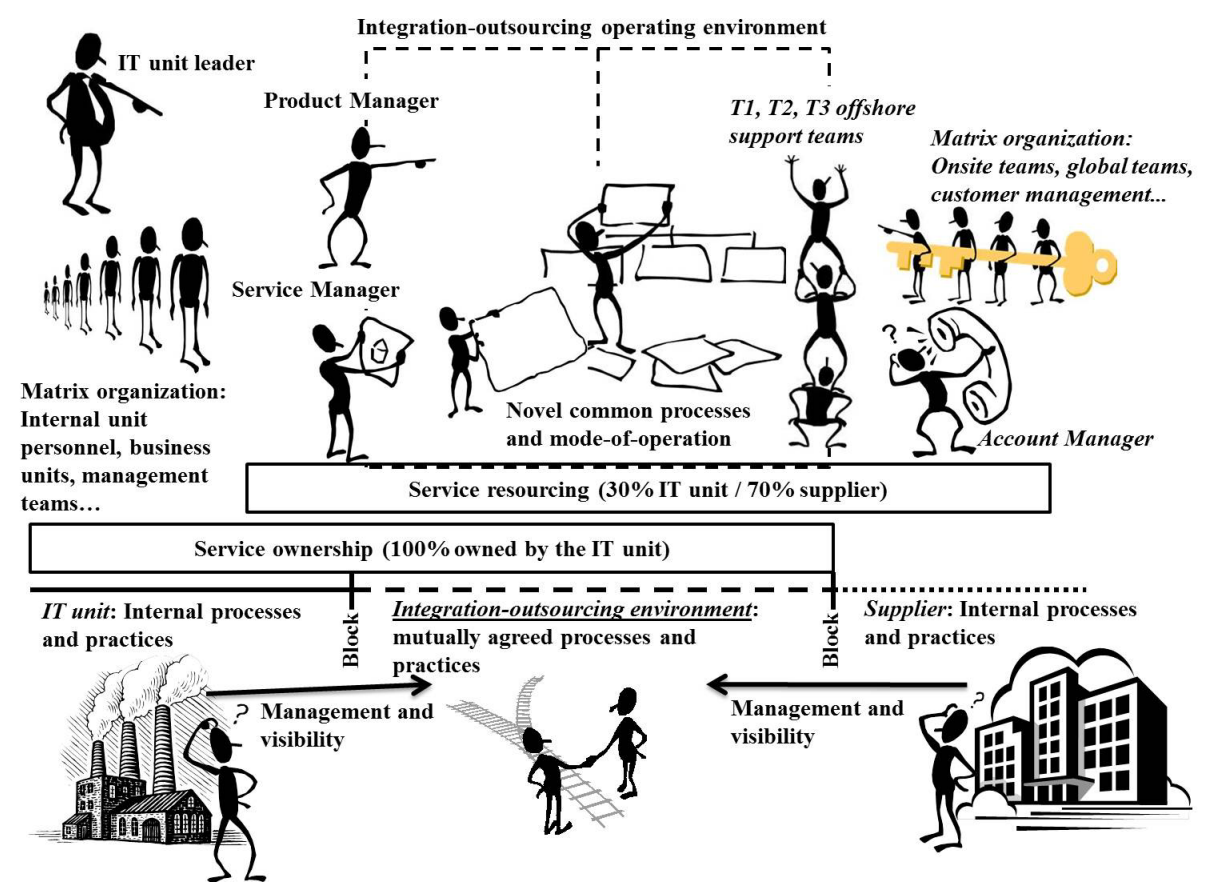

Figure 1. The elements of integration-outsourcing environment. 
compared to in-house operation. It is worthwhile to note that a lack of end-to-end management visibility may negatively impact on the IT service purchasing company's satisfaction perception. The reason is that the IT service purchasing company is not able to influence on the service management and operational level activities (such as, end-to-end processes and practices, costs, resourcing, training and competence development, knowledge of technologies, reporting and measurements practices) in a similar comprehensive manner as operating internally. The lack of end-to-end management may also cause financial impacts for both of the companies. This kind of endto-end management challenge will likely continue as long as the IT services are executed in an integration-outsourcing mode. Therefore, companies may want to establish jointly agreed documentation standards, quality management practices, and management frameworks and best-practices to ensure globally standardized services.

Because of this situation, it was vital that the IT unit had the end-to-end management and operational level visibility. The IT unit was required to react, plan, and manage timely and accurately the IT development and service activities, even when the supplier was responsible for the operational level execution and management.

\subsection{Creating the Global ITIL Processes and Practices between the IT Unit and the Supplier}

Based on our observations and experience, both of the companies had extensive pre-knowledge and experience to implement and operate according to ITIL processes and practices in a global outsourcing context. Therefore, their common target during the planning phase was to prepare in advance for potential future challenges. They also considered that the ITIL best-practices would provide a common language for the globally distributed service teams. The planned integration-outsourcing strategy included also offshoring, and therefore the majority of IT service activities were performed at the suppliers’ offshore competence centers in India and China.

To establish the needed mutual knowledge and processes and practices the IT unit and the supplier jointly defined a novel set of ITIL processes to guide their daily cooperation. Instead of implementing directly the Nokia's existing ITIL processes, they jointly defined and documented the needed processes and practices. The IT unit and the supplier defined over 30 novel ITIL V3 processes to cover the global IT application maintenance and support activities. Even though the total amount of ITIL processes was relatively high, ca. 90 percent of the daily activities were covered with 8 - 10 ITIL processes, for example, incident management services, problem management services, and change management services. The defined ITIL processes described various kinds of IT service delivery activities, such as required tasks, work activities, and roles and responsibilities between the IT unit and the supplier. The jointly agreed practices and mode-of-operation established shared expectations for mutual cooperation and performance levels. The service agreements and performance metrics were created based on the IT service requirements, operational level expectations, and ITIL processes.

The main reasons for using the ITIL processes in the integration-outsourcing environment were: 1) To avoid initiating any service activities without proper documentation; 2) Documents would provide consistent requirements for measuring the service delivery success; 3) Ensuring consistency between the service teams; and 4) To provide a structure for application maintenance and support activities. Nevertheless, the jointly defined ITIL processes did not explicitly describe how the processes and quality and customer-centric ideologies should be implemented into the integration-outsourcing environment and daily operation. In addition, other mode-of-operation activities were also required, such as, implementation plan, communication and cooperation descriptions between the stakeholders, the needed IT solutions, and documentation practices.

Various process documents, such as, the ITIL processes, were needed to describe the service delivery workflows and the customer-centric ideology from a process point of view. The target was to provide a standardized mode-of-operation model and service levels regardless of the individuals who were operating according to the processes. Therefore, in this kind of approach the realized service level should not be constituted based on individuals' success or failure. To achieve the expected service levels and performance, the required processes needed to be defined, documented, trained, and measured. The reason for this was that the IT service end-to-end performance was measured based on these descriptions and targets. The documents were also used as a reference material in contracts between the IT unit and the supplier.

Documentation was an important controlling and guiding element in the integration-outsourcing environment, and because of that, our target is to provide a documentation example how to describe and document ITIL processes. This solution is created based on literature, authors' hands-on experience, and lessons learned from Nokia. The documentation example focuses only on describing the process documentation phases, and therefore, it will not include, for example, detailed work instructions, change management plans, implementation strategies, 
and quality management activities and metrics, which are context, company, and field specific. However, all of the above mentioned elements can provide clarity to daily cooperation and to achieve the expected outsourcing targets. The ITIL processes can be trained to the global service teams based on the process documents.

We used incident management ITIL process as an example. Bartolini et al. [30] wrote that incident management process supports IT organizations to restore normal service operation after a disruption. Help Desk represents the interface for customers to report an IT service disruption. Based on the customer request, the Help Desk creates an incident ticket. The ticket is assigned to specific support groups to fully repair the incident or reassign it to a different support group. Therefore, an incident can have various states and it can be handled by several support groups throughout its lifetime.

Our documentation example (Figure 2) includes seven phases: 1) Process purpose; 2) Process inputs; 3) Process entry criteria; 4) Process workflow; 5) Process steps; 6) Process outputs; and 7) Process exit criteria. Figure 2 emphasizes also the importance of overall management approach and targets, quality practices and metric setting, process implementation, and mode-of-operation and process training.

The phase one target is to describe the overall process purpose. The purpose may be defined as: "To restore normal service operation as quickly as reasonably possible and minimize the adverse impact on business operation”. Hereby, the incident was defined as an unplanned interruption or quality reduction in a service that needs to be corrected. When the process purpose is clarified, the second phase is to describe where the incident inputs may be received, for example, from an event management tool and/or user calls or emails. Besides these inputs, some predefined processes operate also as inputs, for example: Service monitoring and control, corrective maintenance, request fulfillment management, major incident process, change management, and problem management processes. After the inputs, the third phase describes the process entry criteria. For example, a new incident was found in one of the supported applications and the incident has been reported to the support team or the incident has been proactively spotted via predefined processes, such as, service monitoring, corrective maintenance, and adaptive maintenance processes. The phase four describes the process workflow and what are the sequences of the connected steps and work activities among the teams, processes, and IT solutions.

At phase five, the target is to clarify the process steps, such as: responsibilities and work structures, information, teams, policies, and hierarchies. The description can include elements, such as: 1) The support organization is responsible for checking the known error database and FAQ database for similar incidents, analyzing the incident and conduct immediate fixes or workarounds (if possible), and requiring incident resolution approval from the service manager; 2) After the initial analysis phase, the resolution and recovery activities are conducted (for example, apply the potential resolution method and testing). The support organization creates incident resolution change request, and proceeds to raise a request of change ticket for approval; 3) After the recovery activities, the resolution details are updated into the incident management tool and the record is assigned to the support teams. The support organization also updates the incident resolution details into the incident management tool and changes the status as resolved, and communicates it to the customer and confirms the resolution.

After describing the process steps, the phase six defines the process outputs. The outputs description may look like: "Incident has been resolved, the required incident reports have been created (including Key Performance Indicators (KPI) and Performance Indicators (PI) metrics), and the incident management tool has been updated with relevant details, and all relevant stakeholders have been communicated". After the outputs, the final seventh phase describes the process exit criteria. The exit criteria may be defined as: "Incident has been resolved, required communication is done, and required documents are updated". The ITIL process descriptions can be

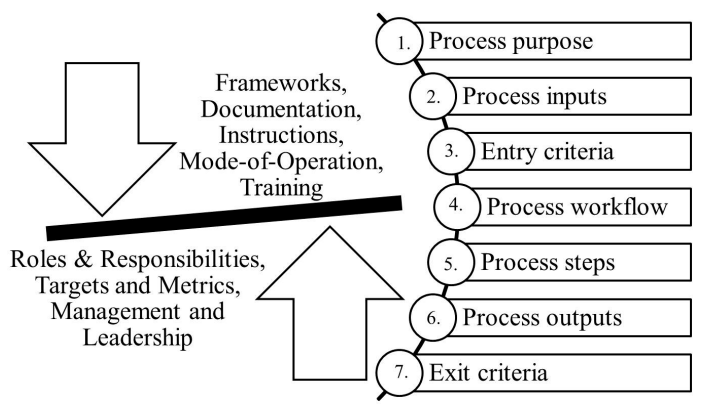

Figure 2. ITIL process documentation. 
used as a guiding frame among the global teams, but the operational level activities and the service purchasing company's core operation is not automatically incorporated into the basic ITIL process structures.

\subsection{Daily Cooperation Challenges}

As in any cooperation, the integration-outsourcing cooperation was not completely trouble-free. Over time, the IT unit indicated dissatisfaction with the service performance and process compliance levels. To analyze the challenges, two Current State Analysis (CSA) interviews were conducted. The CSAs brought out various challenge areas. The IT unit felt that the service delivery levels varied greatly between the IT services and the supplier was not able to provide stable and systematically steady service deliveries. Also, the supplier's success was seen as individual based success, and not based on steady way-of-working practices or consultancy approach. One major challenge was risk management practices, and several challenges were found from competence development and training. The IT unit felt that they had to train and build the supplier's knowledge and skills from the very beginning, even when the supplier was (based on the contracts) responsible for arranging the needed training to their personnel before joining to the global service delivery teams. Because of inadequate training, the new personnel were not able to work comprehensively although the supplier was charging full price from the IT unit. The IT unit expressed that various quality activities, quality evidences, and quality practices were not visible enough. Because of that, the IT unit had to conduct "micro-management" activities to get the needed visibility over the operation. In brief, the daily cooperation challenges were, for example, 1) incoherent global governance and leadership practices; 2) lack of common global quality management practices (such as, metrics, definitions, expectations, and verification/reporting); 3) several communication related challenges (for example, information was not shared to all personnel on time); 4) multisite operations was causing challenges (for example, solving issues was challenging because of the physical/psychological distance); 5) the expectations were not managed efficiently globally; and 6) lack of control of the global operations progress and the needed information was not immediately available.

\section{Results and Analysis}

During the CSAs, we identified several factors that were not directly linked with the ITIL process implementation activities or ITIL compliance levels, but those significantly impacted on the IT unit's satisfaction. These factors originated from the overall integration-outsourcing environment's mode-of-operation, personnel interactions and human relations, and expectation management aspects. During the analysis phase, the expected satisfaction target level was defined by the IT unit's leaders as of 3.5 (in scale of 1 to 5 , where 5 was the highest/ positive value). The results that fell below the target level were identified as unsatisfying and requiring corrective actions. Figure 3 shows the IT unit's satisfaction results. The overall rate of the IT unit's satisfaction was 3.1. Although the cooperation level result was slightly above the target, with a result of 3.53, it was still considered by the IT unit's leaders as an area requiring improvements. Especially, as the IT service delivery result was clearly under the target with a result of 3.26. The five most unsatisfying areas were: 1) Innovation; 2) Risk management; 3) Offshore team cooperation; 4) Knowledge and competencies; and 5) Quality management and visibility.

Some of the IT unit's representatives felt that "the supplier was not taking things seriously enough" and they saw this situation visible especially in the operational level IT service management practices. The CSA results revealed incoherent management and leadership approach. It seemed that the supplier's management and leadership members had differing perceptions and targets. The lack of clear and unified management and leadership approach created an inconsistent situation, which had significant negative impacts on the operational service management. The IT unit said that from their perspective the overall process compliances and producing the outcomes (i.e. customer services) based on the jointly agreed processes and practices were as important as the actual outcomes. The main reason for the process compliance requirement was to ensure standardized service levels and expected interaction among the stakeholders. However, the supplier was mainly concentrating on producing the activities and not considering the process or mode-of-operation compliance as important.

One comment from the supplier's management representative corresponded with this finding:

"I believe that the customer (refers to the IT unit) should concentrate_only_on the outcome, and not on the process, as we are the technical solution provider. So, they should allow us to do the work in the best way as we see it should be done, and then the customer (refers to the IT unit) should concentrate their focus on the actual end-result, and not to the things what happened while we were producing it.” This comment may indicate a de- 


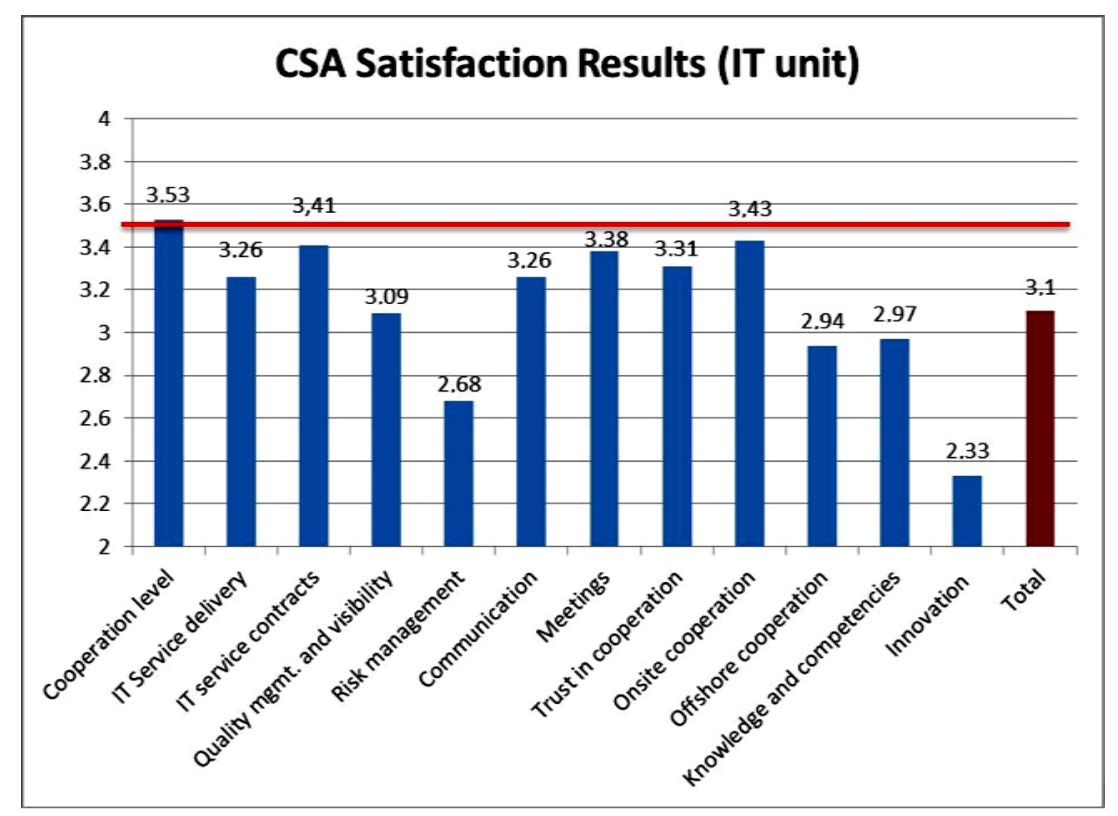

Figure 3. The IT unit's satisfaction results.

sire to change the existing outsourcing practices, or this individual did not understand or did not want to understand the nature of the existing integration-outsourcing agreement. Notably, this kind of situation caused inconsistent communication and confusion among the globally distributed service teams. In addition, some of the roles and responsibilities between the parties were also unclear, which may have caused more confusion.

Several leaders were involved with the IT service management activities. The IT unit had, for example, its own leaders, including the service and product managers, and the IT organization matrix model included also several other teams and stakeholders. The supplier's organization was also a matrix based organization, and they had one customer account (refers to the IT unit) manager responsible for the account level activities, and several managers for onsite and offshore activities. This multi-layer matrix combination may have hindered the overall consensus and communication between the globally distributed teams. In the eyes of the IT unit, the supplier had failed with the expectation management activities. Generally, the situation was: "The supplier assumed that they know what the IT unit expects, and based on that they already know what the IT unit wants. However, in reality neither of the parties knew the real expectations as those were not discussed". The expectation management activities were in a significant role when implementing the new way-of-working practices and customer-centric ideology into the operational level practices.

Although the IT unit and the supplier jointly created the expected ITIL processes and practices for their daily operation, the IT unit felt that the processes were not followed by the supplier as expected: "The ITIL practice following is not 100 percent compliant, and they should attend to ITIL training and train their people better to follow the agreed way-of-working practices". It was agreed that the supplier was responsible for the onsite and offshore personnel training. Still, the IT unit felt that the supplier's personnel were not trained in an adequate level and they had to train and share more information and knowledge to the supplier's personnel than the supplier was giving back to them. The IT unit expressed some doubts whether the supplier was trying to take an advantage of the existing situation by making the IT unit to train the supplier's personnel and then moving the trained personnel to work with other services or companies. As a consequence, the IT unit and the supplier had differing opinions on the ITIL process utilization and training levels.

To measure the ITIL compliance levels, the IT unit and the supplier created the ITIL process assessment tool to assess the process compliance levels. The assessment tool included total of 18 ITIL processes. The total average compliance level for the five main global IT services was 86 percent (Figure 4). It is notable that during the ITIL process definition phase, the IT unit and the supplier did not define any precise ITIL process compliance level requirement. Figure 4 shows also the identified process improvement items in these five IT services.

The ITIL assessment analysis results increased the overall communication among the IT unit, the supplier, and the business representatives, and provided detailed ITIL process compliance information and visibility. The 
ITIL Compliance average\%

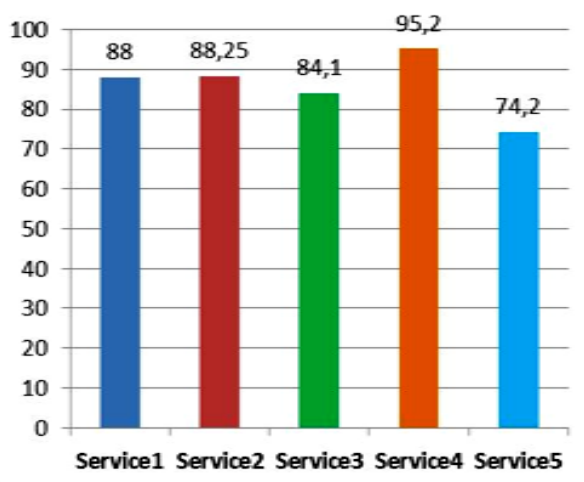

\section{Identified ITIL process} improvement items

- Service1

- Service2

- Service3

- Service4

- Service 5

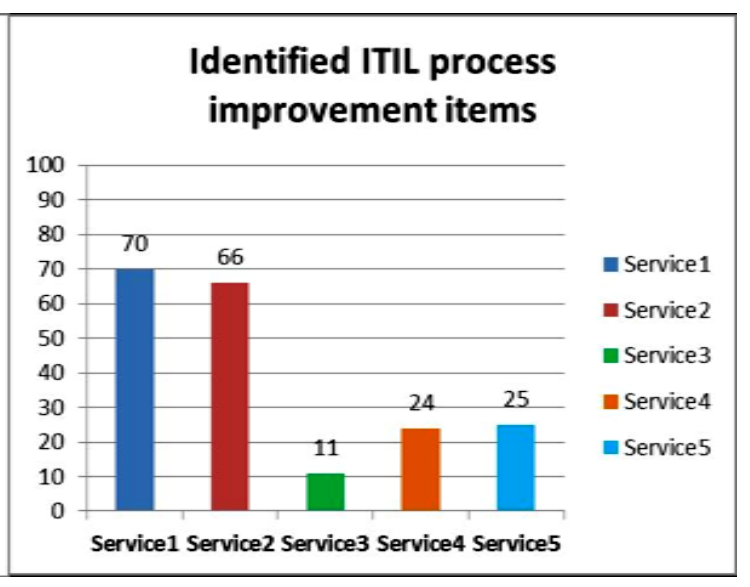

Figure 4. Global ITIL compliance average \% and Identified ITIL process improvement items.

assessments clarified the vagueness of the ITIL compliance levels and the IT unit was satisfied with the overall compliance result in those specific circumstances. This finding has important implications for focusing more on communication, quality practices, quality measurements, and quality reporting. It is notable that the end-to-end compliance result includes both the IT unit's and the supplier's activities, whereas the supplier compliance includes only the supplier's activities. In Figure 4 the compliance result is the supplier compliance.

A total of 150 global ITIL processes were assessed and over 300 process improvement actions were identified. We identified five main ITIL process improvement categories (Table 1): 1) Lack of clear definitions or instructions; 2) Lack of metrics or indicators; 3) Lack of following the processes or instructions; 4) Inadequate reporting or measurement; and 5) Insufficient communication.

The findings indicate that several challenges originated from inadequate quality practices and metrics. The lack of jointly agreed targets and metrics impacted negatively on the IT unit's perception, because the supplier was not able to provide the expected operational level activity reports and quality evidences for the IT unit's verification purposes. Therefore, the IT unit may have questioned some of the supplier's performance results and outcomes.

\section{Discussion and Limitations}

One generic challenge originated from the IT and business strategy alignment requirements. The target was that the IT organization would support the business strategies, provide a link between the business and IT capabilities, and to develop and provide new capabilities and solutions alongside with the business units. Still, the general ITSM target was to ensure that the IT services were aligned with the business needs, business processes, and business development. Because of that the ITIL processes and best practices were used to improve IT service deliveries and to achieve alignment with the business needs. The business needs were derived from the customers' expectations and feedback (when they used the IT applications and help-desk services). As stated also by Shang and Lin [25], there is an imbalance between ITIL principles and customer's expectations. ITIL processes and practices did not provide a direct answer to the customer-centric operation expectation. Generally, ITIL creates alignment between IT capabilities and business needs, but not with customers' needs or providing additional value to the core operation. This finding supports the Hypothesis H1. To achieve customers' satisfaction, the customer-centric operation and incorporating the ideology into the operational processes and practices needs to be the central-point of the end-to-end operation. Similarly, the customer-centric operation ideology needs to be incorporated into the integration-outsourcing environment's operational processes and practices. This would clarify and guide the daily cooperation when all parties share the common target to ensure customers' satisfaction.

Another challenge in this integration-outsourcing environment was the definition of a customer. In this case, there were several customers. The main customer-categories were: 1) End-consumers (contacted the servicedesks); 2) Business representatives (defined the business needs and business-roadmaps); and 3) The IT unit (owned the IT solutions and services). Although the end-consumers were the most important customers, the supplier's paying customer was the IT unit. The IT unit owned the IT applications and services and created the out- 
Table 1. ITIL assessment findings and improvement areas.

\begin{tabular}{|c|c|c|}
\hline Category & Type & Examples \\
\hline \multirow{2}{*}{ Category 1} & \multirow{2}{*}{ Definitions } & No formal documentation in place \\
\hline & & Categories, impact, urgency, and priority levels not in line with other processes \\
\hline \multirow{4}{*}{ Category 2} & \multirow{4}{*}{ Metrics } & Service Level Agreement (SLA) times are not defined \\
\hline & & Metrics are not defined \\
\hline & & No threshold timeline defined to transfer requests between teams \\
\hline & & Key Performance Indicators (KPI) are not defined \\
\hline \multirow{4}{*}{ Category 3} & \multirow{4}{*}{ Process } & Problems are not tracked and managed according to the process and SLA \\
\hline & & No defined escalation process to ensure timely resolution \\
\hline & & Need to strengthen the integration between other processes \\
\hline & & $\begin{array}{l}\text { Not recording the needed information, e.g., incident detection, logged, approved, resolution and } \\
\text { closure timing are not captured. }\end{array}$ \\
\hline \multirow{3}{*}{ Category 4} & \multirow{3}{*}{ Reporting } & No periodical process reviews to identify any potential improvements \\
\hline & & No exclusive reports generated to capture the total amount of activities per month \\
\hline & & All defined metrics are not measured \\
\hline Category 5 & Communication & Status information and estimated resolution timelines of incidents are not proactively communicated \\
\hline
\end{tabular}

sourcing contracts with the supplier. It is possible that the supplier misunderstood their main operative customer or they wanted to change the existing selective outsourcing structure and to work directly with the business unit. Still, fully technical solution provider mode was not enough anymore for providing the needed capabilities and the IT unit was responsible for several other capabilities that the supplier was not aware of. Therefore, clarity of the responsibilities and operating limits are in a significant role when implementing global outsourcing cooperation practices. This finding supports also Hypothesis H1.

Our results indicate that the ITIL process implementation alone did not ensure the IT unit's satisfaction. The need of well-managed change implementation, management and leadership practices, and customer-centric ideology were critical to achieve the transformation regardless of good ITIL knowledge level. Accordingly, there was a need to implement and define also other operational practices and frameworks to ensure the IT unit's satisfaction. Following are our six findings having similarities with the Sharifi et al. [16] findings.

1) Active and participative management, from both of the parties, is required and the leaders must recognize their role in the change execution. Both of the parties are needed to commit and manage the integration-outsourcing environment together, and one-sided management approach would not be sufficient. Based on our experience and research findings, it is important that the leaders recognized their role as part of the change execution in order to achieve the planned targets. The leaders are needed to promote and require common way-ofworking operation, interactive collaboration, team working, and improved management and leadership practices including clarity of the roles and responsibilities. The end-to-end management and the service operation visibility need to be enabled in the integration-outsourcing environment and to ensure unified communication. From the leadership's perspective, it is important to understand the practical challenges on the field to clarify and manage the possible cooperation related challenges. This finding verifies that efficient coordination in a global selective outsourcing environment is critical.

2) Clear ITIL processes are good way to standardize the execution of activities, but more focus is needed to clarify and train the operational level knowledge, the objectives of the operation, and way-of-working practices. The IT unit and the supplier spent a lot of time to define the ITIL process documents. The documents were needed to establish the overall integration-outsourcing cooperation structure. Therefore, less time and effort were used to create, for example, practical work instructions. Eventually, the process documents became more important from contractual point of view than defining the daily cooperation practicalities. Spending a lot of 
time to define the processes does not necessarily guarantee a successful adaptation and way-of-working transformation. There is a need for efficient and participative management and training, because processes are providing only guidelines instead of all-inclusive operation and management solutions. This finding supports the importance of efficient and timely training and information sharing.

3) Named process owners are needed to develop, manage, and train the processes and practices. Both of the companies had internal process owners, but "no-one” owned the jointly defined ITIL processes in the integration-outsourcing environment. Hence, no-one ensured the process compliances, or provided guidance and training, or verified the global work instructions. Apparently, the IT unit and the supplier may have been too ambiguous during the implementation phase. As both of the companies were familiar with the generic ITIL practices, they wanted to implement majority of the ITIL processes at once to achieve fast results and benefits. However, implementing the novel ITIL processes, practices, and mode-of-operation included also challenges. This finding supports the criticality of global coordination. There were also other training and skills related challenges. If the supplier does not have the needed process expertise and knowledge in place, then the IT service purchasing company will have an unrealistic expectation of supplier's quality and output levels. The IT service purchasing companies need to be prepared to assist the suppliers in achieving the targets, competency, and expectations. At the end, the IT service purchasing company will face the impacts. But, the supplier should not transfer their training responsibility to the IT service purchasing company if they have agreed to provide the needed process and mode-of-operation training.

4) Quality management and quality practices should not be outsourced. Over time, the IT unit started to require more quality practices and quality evidences. The IT unit wanted to achieve better service quality performance, but the quality practices were not jointly defined and implemented. Therefore, in an integration-outsourcing situation the companies should define and implement also other solutions, for example, quality management practices and to establish quality and customer focused operation practices. The quality expectations and practices might be useful to include into the contracts, but it might also give an indication to the supplier to increase the service price. The current study found that quality and customer-centric operations management should not be outsourced to an external party or expecting them to be accountable for the end-to-end quality onbehalf-of the IT service purchasing company. Performance results and satisfaction surveys may be used as success indicators, but assessing the quality and customer-centric operations performance without defined targets, metrics, or definitions is not sufficient.

5) A long-term outsourcing investment realization plan is required. Being able to clearly communicate the outsourcing targets, the IT service purchasing company should have a clear vision what they are trying to achieve from the outsourcing activities and how the operations will be coordinated globally (supports the Hypothesis H1). As in this case, the implementation and transformation periods were relatively long, and therefore it was not possible to achieve the expected business benefits within a short period of time. Because of this, a long-term investment realization plan and measurement methods are needed to measure the actual target realization level. Also, enough time should be reserved to exploit the agreed strategy before changing it. Otherwise, there will not be enough time to realize the expected targets or implement the needed change activities.

6) In an integration-outsourcing situation, the IT service purchasing company needs to actively ensure that their expectations will be fulfilled as they expect. As part of the service proposal, the supplier offered that they would lead the knowledge-transfer activities and to establish the operative service practices. Over time, the IT unit's knowledge and expectations became more precise from the supplier perspective. Based on the IT organization's strategic decision, the IT unit had to start the required outsourcing activities and backsourcing was not an option. In the course of time, the IT unit's expectations and focus moved more on the IT services, operational level activities, produced outcomes, quality, and performance. At the end, the IT unit had to take the leading role to achieve the planned targets to satisfy its customers. This finding also verifies that the service purchasing company needs to focus on global coordination and implementing quality and customer-centric operations (supports the Hypothesis H1).

Naturally, we acknowledge that this study has some limitations. The research findings are based on action research observations, interviews, and questionnaires. The data is from only one IT unit and from one supplier and its onsite and offshore teams. This can limit the generalization of results, and therefore, further research from different companies and industry fields are needed to validate and elaborate the findings. It is notable that all companies do not have the objective of obtaining benefits from various outsourcing based strategies or implement ITIL processes and practices into their operations as extensively as in this research. Although the purpose 
was to open viewpoints to the global ITIL implementation in the integration-outsourcing environment, it does highlight the need for further research. A future research with more focus on quality practices in a global integration-outsourcing environment is therefore suggested, and analyzing the executed corrective actions and next steps at Nokia, and the effects of those on the IT service purchasing company's satisfaction.

\section{Conclusions}

Nokia was an ideal as a case company when it started its IT service transformation activities. The global transformation activities in the IT unit made it possible to analyze the trivial integration-outsourcing challenges that emerged during the transformation. This research has important implications to substantially stress quality, communication and training, and management practices in a selective-outsourcing situation. In this research, these elements had significant and direct impacts on the IT service purchasing company's satisfaction. Similarly, good ITIL process and practices knowledge and experience may have reduced the overall adaption time, but evidently it did not remove the challenges. The need of efficient and timely change management activities remains to ensure customer-centric operation implementation into the integration-outsourcing activities. Efficient training and guidance were needed to achieve the expected IT service levels and process compliance. Our findings can indicate that it requires a substantially long period of time to complete the global IT service modeof-operation transformation and service stabilization, even when being notably familiar with the ITIL practices. It is worthwhile to note that in an integration-outsourcing environment two companies were jointly executing the selected activities based on the predefined way-of-working models. However, the companies may have separate and even contradictory expectations and targets. Therefore, the end-to-end management and visibility are not possible in a similar way as operating internally.

In an integration-outsourcing situation, we identified that it is critical that the IT service purchasing company has accurate knowledge of their current situation and future plans. They should identify what is their core knowledge and based on this knowledge they should identify what should be kept in-house and what can be selectively outsourced. The IT service purchasing company should clearly define their outsourcing targets and how the activities need to be managed, measured, and communicated. It is important that the IT service purchasing company stresses the importance of daily cooperation structures, knowledge of how to provide value adding to the core operation, ideologies, practices, and quality standards to ensure the expected service levels and standardized service delivery to their customers. This may increase the capabilities to jointly define more accurate daily cooperation practices among the parties and to conduct timely and efficiently the needed corrective and preventive actions to satisfy the customers.

\section{References}

[1] Worthen, B. (2005) ITIL Power: Why the IT Infrastructure Library Is Becoming the Most Popular Process Framework for Running IT in America, and What Is Can Do for You. CIO, 18, 1-5.

[2] Gartner (2014) Gartner Says Worldwide IT Spending on Pace to Grow 2.1 Percent in 2014. http://www.gartner.com/newsroom/id/2783517

[3] Gartner (2013) Gartner Says Worldwide IT Outsourcing Market to Reach \$288 Billion in 2013. http://www.gartner.com/newsroom/id/2550615

[4] Davenport, T. (2005) The Coming Commoditization of Processes. Harvard Business Review, 86, 100-108.

[5] Sousa, R. and Voss, C. (2007) Operational Implications of Manufacturing Outsourcing for Subcontractor Plants: An Empirical Investigation. International Journal of Operations \& Production Management, 27, 974-997.

[6] McIvor, R. (2013) What Do We Know about Services Outsourcing? ICAS, Edinburgh.

[7] Han, K. and Mithas, S. (2013) IT Outsourcing and Non-IT Operating Costs. MIS Quarterly, 37, 315-331.

[8] Gopal, A. and Gosain, S. (2010) The Role of Organizational Controls and Boundary Spanning in Software Development Outsourcing: Implications for Project Performance. Information Systems Research, 21, 960-982.

[9] Oshri, I., Kotlarsky, J. and Willcocks, L. (2007) Managing Dispersed Expertise in IT Offshore Outsourcing: Lessons from Tata Consultancy Services. MIS Quarterly Executive, 6, 53-65.

[10] McIvor, R. (2008) What Is the Right Outsourcing Strategy for Your Process? European Management Journal, 26, 24-34.

[11] Ang, S. and Cummings, L. (1997) Strategic Response to Institutional Influences on Information Systems Outsourcing. Organization Science, 8, 235-255. http://dx.doi.org/10.1108/17538290910973349 
[12] Jap, S.D. and Anderson, E. (2003) Safeguarding Interorganizational Performance and Continuity under Ex Post Opportunism. Management Science, 49, 1684-1701. http://dx.doi.org/10.1287/mnsc.49.12.1684.25112

[13] Veltri, N., Saunders, S. and Kavan, C.B. (2008) Information Systems Backsourcing: Correcting Problems and Responding to Opportunities. California Management Review, 51, 50-76. http://dx.doi.org/10.2307/41166468

[14] ITIL (2013) ITIL: The Basics White Paper. http://www.best-management-practice.com/gempdf/ITIL_The_Basics.pdf

[15] ITIL (2007) An Introductory Overview of ITIL V3. https://www.best-management-practice.com/gempdf/itSMF_An_Introductory_Overview_of_ITIL_V3.pdf

[16] Sharifi, M., Ayat, M., Rahman, A.A. and Sahibudin, S. (2008) Lessons Learned in ITIL Implementation Failure. Proceedings of the International Symposium on Information Technology, Kuala Lumpur, 26-28 August 2008, 1-4.

[17] Somers, T.M. and Nelson, K. (2001) The Impact of Critical Success Factors across the Stages of Enterprise Resource Planning Implementations. Proceedings of the 34th Hawaii International Conference on System Sciences, IEEE Computer Society, Los Alamitos.

[18] Office of Government Commerce, OGC (2010) ITIL Planning to Implement Service Management. Handbook from the Official Publisher of ITIL, TSO (The Stationery Office).

[19] Shang, S. and Lin, S.-F. (2010) Barriers to Implementing ITIL-A Multi-Case Study on the Service-Based Industry. Contemporary Management Research, 6, 56-70.

[20] Douglas, T.J. and Fredendall, L.D. (2004) Evaluating the Deming Management Model of Total Quality in Services. Decision Science, 35, 393-423. http://dx.doi.org/10.1111/j.0011-7315.2004.02569.x

[21] Scott, J. (2005) ISO 9000 in Service: The Good, the Bad and the Ugly. Quality Progress, 38, 42-48.

[22] Williams, C. (2007) Research Methods. Journal of Business \& Economic Research, 5, 65-72.

[23] Johnson, R.B. and Onwuegbuzie, A.J. (2004) Mixed Methods Research: A Research Paradigm Whose Time Has Come. Educational Researcher, 33, 14-26. http://dx.doi.org/10.3102/0013189X033007014

[24] Näslund, D. (2002) Logistics Needs Qualitative Research-Especially Action Research. International Journal of Physical Distribution \& Logistics Management, 32, 321-338. http://dx.doi.org/10.1108/09600030210434143

[25] Meyer, J. (2000) Using Qualitative Methods in Health Related Action Research. British Medical Journal, 320, $178-181$. http://dx.doi.org/10.1136/bmj.320.7228.178

[26] Bernard, H. (1988) Research Methods in Cultural Anthropology. Sage, Newbury Park.

[27] Crabtree, B. and Miller, W. (1999) Doing Qualitative Research. 2nd Edition, Sage, Thousand Oaks, 18-20.

[28] Dicicco-Bloom, B. and Crabtree, B.F. (2006) The Qualitative Research Interview. Medical Education, 40, $314-321$. http://dx.doi.org/10.1111/j.1365-2929.2006.02418.x

[29] Creswell, J. (2003) Research Design: Qualitative, Quantitative, and Mixed Methods Approaches. 2nd Edition, SAGE Publications, Thousand Oaks.

[30] Bartolini, C., Stefanelli, C. and Tortonesi, M. (2008) A Simulation Tool for the Optimization of the IT Incident Management Process. Proceeding of the 19th IFIP/IEEE International Workshop on Distributed Systems: Operations and Management, Samos Island, 25-26 September 2008, 83-94. 
Scientific Research Publishing (SCIRP) is one of the largest Open Access journal publishers. It is currently publishing more than 200 open access, online, peer-reviewed journals covering a wide range of academic disciplines. SCIRP serves the worldwide academic communities and contributes to the progress and application of science with its publication.

Other selected journals from SCIRP are listed as below. Submit your manuscript to us via either submit@scirp.org or Online Submission Portal.
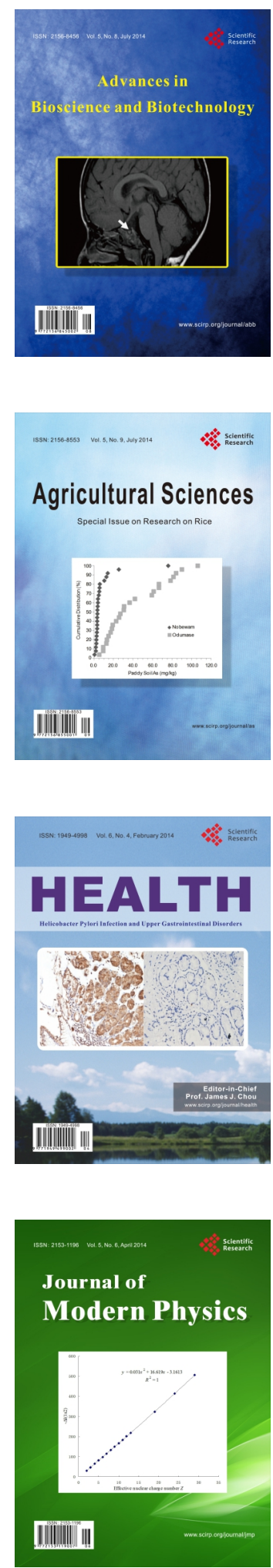
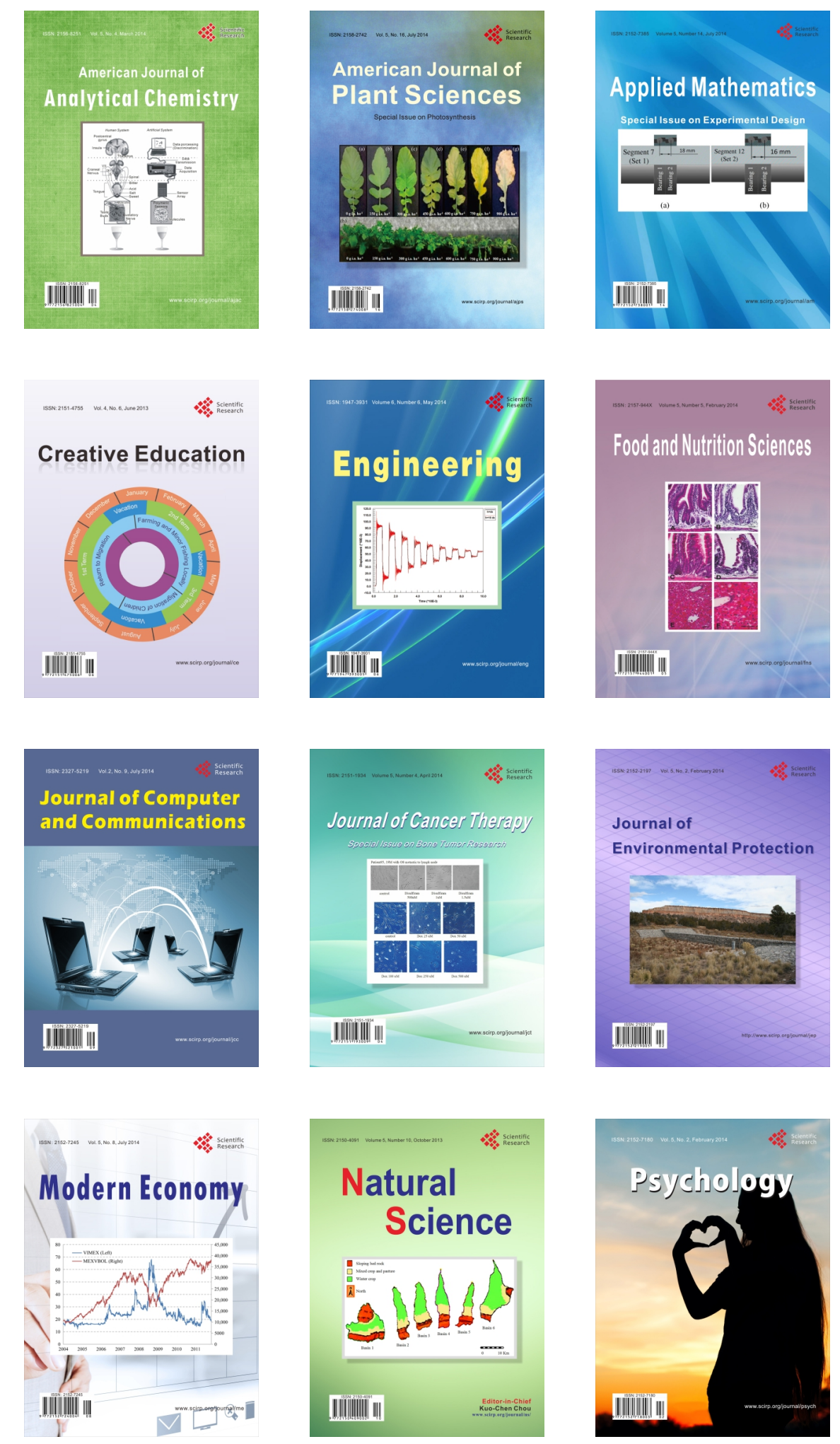